\title{
Lung injury related to extreme environments
}

\author{
Yochai Adir ${ }^{1,2}$ and Alfred A. Bove ${ }^{3}$ \\ Affiliations: ${ }^{1}$ Pulmonary Division, Faculty of Medicine, Lady Davis Carmel Medical Center, Haifa, Israel. \\ ${ }^{2}$ Technion - Israel Institute of Technology, Haifa, Israel. ${ }^{3}$ Dept of Medicine, Section of Cardiology, Temple \\ University School of Medicine, Philadelphia, PA, USA.
}

Correspondence: Yochai Adir, Pulmonary Division, Faculty of Medicine, Lady Davis Carmel Medical Center, 7 Michal St, 34362 Haifa, Israel. E-mail: adir-shdzahav.net.il

0 @ERSpublications

Lung injury is a well understood and preventable consequence of water immersion while swimming and diving http://ow.ly/AOdvg

As extreme sports become more popular, related respiratory injury may compromise the athlete's performance and result in morbidity and even mortality. In this article we will discuss different lung injuries in relation to performing different activities in an extreme environment.

\section{Hydrostatic lung injuries}

The evolution of fish to amphibians, reptiles to endothermic birds and mammals has been accompanied by a progressively thinner pulmonary blood gas barrier, to accommodate the constraint of increased oxygen uptake and carbon dioxide output [1]. Accordingly, pulmonary circulation has evolved as a separate high flow-low pressure system. In humans, mean pulmonary artery pressures (PAP) are $8-20 \mathrm{mmHg}$, pulmonary wedge pressures are $5-14 \mathrm{mmHg}$ and pulmonary capillary pressures are $8-12 \mathrm{mmHg}$ [2]. A low-pressure regimen preserves the integrity of an alveolar capillary membrane only $0.3 \mu \mathrm{m}$ thick. However, this structure is vulnerable to increased pressures during strenuous exercise or environmental hypoxic exposure as a cause of stress failure of the pulmonary capillaries and accumulation of extravascular lung water [3]. Reports of lung injury related to extremes of exercise and variations in ambient pressure and altitude confirm this vulnerability. The resulting lung injury takes the form of noncardiogenic pulmonary oedema.

The occurrence of noncardiogenic pulmonary oedema and pulmonary haemorrhage has been described in relation to a variety of disorders related to auto- and exogenous immunological reactions, infections and certain inhalants. However, numerous reports of lung injury manifesting as pulmonary oedema with associated haemorrhage have been described more recently in relation to immersion underwater, swimming, extreme exercise and exposure to altitude. In addition, pulmonary oedema resulting from negative intra-alveolar pressure has been described in the anaesthesia literature and may play a role in exercise- and immersion-induced pulmonary oedema.

\section{Haemodynamically induced pulmonary oedema}

A single mechanism responsible for production of noncardiogenic pulmonary oedema related to immersion, altitude and exercise has not been identified. However, a combination of haemodynamically related factors, alterations in capillary integrity, increased blood volume and increased cardiac output may all contribute to the syndrome. WEST et al. [4] described exercise-induced pulmonary haemorrhage in race

For editorial comments see page 401.

Received: July 312014 | Accepted after revision: Aug 222014

Conflict of interest: Disclosures can be found alongside the online version of this article at err.ersjournals.com

Provenance: Submitted article, peer reviewed.

Copyright CERS 2014. ERR articles are open access and distributed under the terms of the Creative Commons Attribution Non-Commercial Licence 4.0. 
horses exercising at high workloads. The authors studied the haemodynamics in one horse susceptible to exercise-induced pulmonary haemorrhage and noted a marked increase in mean PAP to $138 \mathrm{mmHg}$ at a high running workload, and found blood in the trachea of the animal after exercise. They examined the lungs of several horses susceptible to exercise-induced pulmonary haemorrhage and concluded that those animals had a wall thickness of $<0.51 \mu \mathrm{m}$ in $30 \%$ of their capillaries. They estimated that the wall stress on capillaries with a wall thickness $<0.51 \mu \mathrm{m}$ would result in high wall stress and capillary rupture under conditions of high pulmonary capillary pressure. The elevated pulmonary arterial and venous pressure that occurred during exercise was adequate to result in capillary injury and leakage of blood into the alveolar spaces. The study by WEST et al. [4] identified several factors that could explain exercise-induced pulmonary haemorrhage. Elevated pulmonary arterial and venous pressures and transcapillary pressure gradients were all important contributors. WEST et al. [4] also considered that a remodelling process in the lung capillaries resulted in reduced capillary strength and a propensity to rupture under conditions of increased capillary pressure [5]. These findings led to an analysis of factors that cause elevated pulmonary arterial and venous pressures and reductions in alveolar pressure in otherwise normal animals and humans.

\section{Pulmonary venous and arterial pressure during exercise}

As cardiac output increases with increasing exercise output, both heart rate and stroke volume increase initially, but as demand increases the ventricle tends towards a constant stroke volume and increases cardiac output by increasing heart rate [6]. The ability of the ventricle to relax and fill rapidly in diastole defines the relationship between stroke volume and total cardiac output. In well-trained athletes, for example, the left ventricle relaxes more rapidly than in untrained individuals [3], thereby maintaining a low end diastolic pressure at high levels of cardiac output. The rising end diastolic pressure reflected into the lung capillaries ultimately coupled with the high capillary flow at high levels of exercise [2], results in fluid and blood extravasation from the lung capillaries to the interstitial and alveolar spaces. In turn, the alveolar fluid can reduce oxygen diffusing capacity and result in hypoxaemia with reflex pulmonary vasoconstriction [2]. This mechanism can be affected by increased blood volume, reduced left ventricular compliance and reduced myocardial function. BARTESAGHI et al. [7] suggested that a ratio of capillary volume to alveolar volume that increases with exercise reduces the risk of exercise-induced capillary leakage. In situations where intraalveolar pressure is reduced during inspiration, the capillary transmural gradient will be further increased and contribute to leakage from the capillaries to the interstitial and alveolar spaces. PAP is also increased at high levels of exercise. Recent studies in endurance runners have demonstrated transient right ventricular dysfunction, which is thought to be related to a combination of pressure and volume overload on the right ventricle during sustained exercise at high cardiac output levels [8]. Pulmonary pressure reflects left atrial pressure, plus the pressure drop across the pulmonary vascular bed that is increased under conditions of high cardiac output. The well-known relationship of pulmonary hypertension to left-to-right shunting at the atrial or ventricular level [9] reflects the fact that PAP will increase under conditions of high pulmonary blood flow, which is found with left-to-right shunts and high levels of exercise. This combination of physiological responses provides a basis for understanding the pulmonary oedema that occurs with swimming, diving and exercise.

\section{Immersion pulmonary oedema}

Immersion pulmonary oedema appears to be a disorder particularly noted in scuba divers who breathe compressed air underwater through a demand regulator, and in swimmers who are exercising at high workloads while in the water. The syndrome in divers has been described in a number of clinical reports $[9,10]$. It is characterised by sudden onset of dyspnoea while underwater breathing compressed air. The diver ascends to the surface with severe dyspnoea and commonly describes a cough producing blood-tinged sputum. Similar findings can occur in swimmers related to exercise while immersed [11-16]. Auscultation reveals bibasilar rales and the chest radiograph shows a typical pulmonary oedema pattern. Chest computed tomography demonstrates diffuse patchy ground-glass densities throughout both lung fields that clear within 4-7 days. The disorder is self-limiting, usually responds to intravenous diuretics and, when reported, cardiac tests including echocardiography and coronary angiography are usually normal. SHUPAK et al. [17] found a reduced forced vital capacity and forced expiratory volume in $1 \mathrm{~s}$ in naval swimmers who developed swimming-induced pulmonary oedema. Further reduction in lung volume was noted in the presence of pulmonary oedema. WILMSHURST et al. [18] studied a group of divers who developed immersion pulmonary oedema and found they reacted to cold exposure and increased oxygen partial pressure with a significant rise in blood pressure, which was significantly greater than the changes recorded in a group of subjects who did not experience immersion pulmonary oedema when diving. FRASER et al. [19] studied a group of divers exercising at increased pressure and at sea level. They found similar increases in PAP and pulmonary capillary wedge pressure. Their data suggest that neither hyperoxia nor increased ambient pressure alter pulmonary haemodynamics during immersed exercise. However, minute ventilation and 
respiratory frequency were lower in the group exposed to increased partial pressure of oxygen. In a study of 22 scuba divers with normal cardiac function who developed pulmonary oedema while diving, COULANGE et al. [20] hypothesised that extreme exercise, hyperoxia, cooling and hydrostatic pressure contributed to the occurrence of pulmonary oedema. Their subjects developed pulmonary oedema during the ascent phase of their dives. SHEARER et al. [21] reported that brain natriuretic peptide levels were increased in six naval swimmers during strenuous swimming-induced pulmonary oedema. They interpreted their observations as indicating that a cardiac component may contribute to swimming-induced pulmonary oedema. Their data are consistent with the concept that failure of left ventricular relaxation results in increased pulmonary capillary pressure and consequent capillary leakage. Moon et al. [22] suggested that gas density effects on intra-alveolar pressures and dead space/tidal volume ratio, and blood volume shifts into the pulmonary capillary circulation caused by immersion, altered lung mechanics enough to reduce exercise capacity. This combination of effects would also result in higher transcapillary pressures during exercise while immersed and breathing compressed gas. ZAVORSKY [23] reviewed published reports of exercise-induced pulmonary oedema in 137 subjects who underwent prolonged submaximal exercise or short-duration maximum exercise. They reported a $16 \%$ incidence of pulmonary oedema following prolonged exercise, and a $65 \%$ incidence from short-duration, highintensity exercise. While these studies were performed in a dry environment, their data suggest that the type of exercise performed while swimming or diving contributes to the risk of pulmonary oedema.

\section{Exercise-induced pulmonary oedema}

While some controversy exists on the presence of exercise-induced pulmonary oedema [24-26], numerous case reports demonstrate the presence of pulmonary oedema after prolonged or high-intensity exercise [27], which, upon further evaluation, appears to be unrelated to abnormal cardiac function. Evidence for pulmonary oedema has been shown in competitive rowers [28], during exertion in dry cold environments and in cases of emotional stress and sexual intercourse [29], in addition to long distance runners and triathletes [30-40] and competitive cyclists [41, 42]. The importance of mild oedema in reducing exercise capacity has been questioned [43]. Experimental studies demonstrate evidence of heterogeneous lung perfusion following prolonged exercise [44]. There is evidence that hyponatraemia, which particularly occurs in marathon running, contributes to pulmonary oedema [45-53]. This occurs especially in marathon runners who ingest excess water while racing. The combination of high water intake, loss of electrolytes from sweating, and antidiuretic hormone release is probably the cause.

Symptomatic cerebral oedema often accompanies pulmonary oedema, and both entities require urgent intervention aimed at restoring normal plasma sodium concentration.

\section{High-altitude pulmonary oedema}

High-altitude pulmonary oedema is a potentially fatal condition that occurs in previously healthy subjects within hours or days of a rapid ascent to high altitudes (fig. 1) [54-56]. Exercise and cold are predisposing factors. Symptoms consist of dyspnoea, reduced exercise tolerance, and dry cough that eventually produces frothy sputum with haemoptysis. Clinical examination shows tachypnoea, tachycardia, cyanosis and crepitations on auscultation. The incidence of high-altitude pulmonary oedema is estimated to be around $1 \%$ in subjects who rapidly ascend to altitudes $>4000 \mathrm{~m}$ in $<24 \mathrm{~h}$. It is not affected by age, sex or preexisting fitness. It increases to $50 \%$ in subjects with a previous history of high-altitude pulmonary oedema, and decreases with acclimatisation. High-altitude pulmonary oedema is uncommon below $2000 \mathrm{~m}$, and rapidly and completely reverses within $24 \mathrm{~h}$ after returning to a sea level altitude.

A hypoxia-induced increase in PAP is a sine qua non condition for high-altitude pulmonary oedema [54-56]. While hypoxic pulmonary vasoconstriction in the human species is usually mild or even absent, high-altitude pulmonary oedema-susceptible subjects typically have a strong response. Any additional cause of increased PAP, such as exercise, a pre-existing restrictive pulmonary vascular bed [57] or latent pulmonary arterial hypertension [58], increases the risk of high-altitude pulmonary oedema. There is also a contribution of sympathetic nervous system activation related to hypoxic brain oedema as a cause of pulmonary vasoconstriction and blood volume shifts from the systemic to pulmonary vascular beds [56]. However, high-altitude pulmonary oedema can be prevented by the intake of pulmonary vasodilating interventions, such as nifedipine, tadalafil and, somewhat surprisingly, dexamethasone, indirectly underscoring the major role of pulmonary vasoconstriction $[59,60]$.

Right heart catheterisation studies in subjects with high-altitude pulmonary oedema have revealed severe pulmonary hypertension with a normal pulmonary artery wedge pressure [61]. The analysis of PAP decay curves after balloon occlusion showed an unchanged longitudinal distribution of resistances, allowing for calculation of an effective pulmonary capillary pressure, on average about halfway between mean and wedged PAP. Thus, subjects with a strong hypoxic pulmonary vasoconstriction response may easily present 


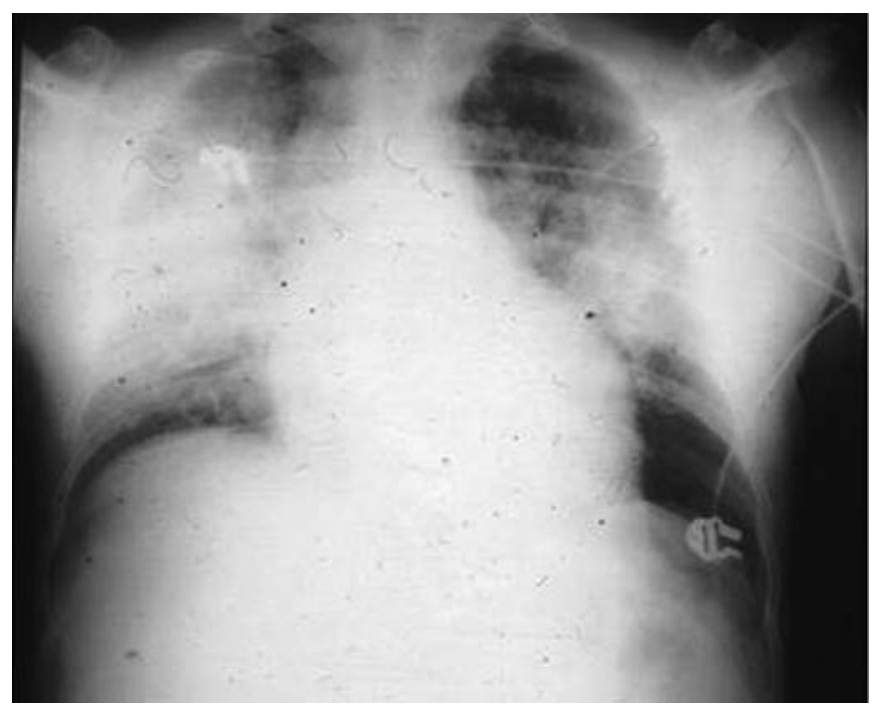

FIGURE 1 Chest radiograph from a subject with high-altitude pulmonary oedema investigated a few hours after ascending to the Capanna Regina Margherita hut at $4559 \mathrm{~m}$ in the Italian Alps. The chest radiograph shows an enlarged heart with "butterfly shape" opacities in both lung fields. Image courtesy of R. Naeije, Dept of Cardiology, Erasme University Hospital, Brussels, Belgium.

with a pulmonary capillary pressure $>20 \mathrm{mmHg}$, which is the cut-off value for excessive filtration and lung water accumulation [62].

Hypoxic pulmonary vasoconstriction is inhomogeneous [63]. This causes uneven distribution of blood flow in oedematous lungs with higher pressures and further increase in filtration in overperfused lung regions [54-56]. Pressures that are too high damage the capillary walls (stress failure), resulting in a capillary leak that is rich in albumin and red blood cells, as shown by bronchoalveolar lavage studies in subjects with high-altitude pulmonary oedema [64].

This pathophysiology is remarkably similar to that of strenuous exercise-induced lung oedema. Recent studies have shown that mean PAP-flow relationships vary from 0.5 to $3 \mathrm{mmHg} \cdot \mathrm{L}^{-1} \cdot \mathrm{min}^{-1}$, a six-fold variation associated with PAP $>40 \mathrm{mmHg}$ during high-intensity dynamic exercise at cardiac outputs $>25-30 \mathrm{~L} \cdot \mathrm{min}^{-1}$ in some athletes [65]. Normal but steep PAP-flow relationships may limit exercise capacity through excessive afterloading of the right ventricle [44]. However, redistribution of blood flow occurs [64] and pulmonary capillary pressures may still be high enough to cause capillary stress failure in highly motivated athletes.

\section{Negative pressure pulmonary oedema}

For over a decade, anaesthesiologists have reported the risk of developing acute pulmonary oedema when an individual develops laryngospasm and attempts are made to ventilate against a closed glottis [66, 67]. This has also been reported in healthy athletes undergoing anaesthesia [68], and in patients with partially obstructed airways [69]. UDESHI et al. [70] described two types of negative pressure pulmonary oedema. Type I is usually found in adults and is caused by forceful inspiration in the presence of an acute airway obstruction. A common cause is laryngospasm following general anaesthesia. Type II usually occurs after relief of a chronic partial airway obstruction (post-obstruction pulmonary oedema). LANG et al. [71] described the response to negative intrathoracic pressure as an increased pulmonary blood volume and elevated pulmonary venous pressure that increase the transcapillary pressure and allow exudation of fluid into the interstitial and alveolar space. The negative alveolar pressure further increases the transcapillary gradient, further increasing fluid extravasation into the alveoli. In immersion pulmonary oedema associated with scuba diving, negative pressure breathing can occur due to faulty breathing equipment or due to the forceful inspiration of the higher density compressed air breathed at depth. The resulting fall in intraalveolar pressure increases the gradient between intracapillary and alveolar pressure, resulting in excess stress on pulmonary capillaries and production of pulmonary oedema [72]. The increased pulmonary blood volume associated with immersion [73] also contributes to a higher capillary to alveolar pressure gradient. It is possible that at high ventilatory rates associated with extreme exercise, negative alveolar pressures could develop, particularly in the presence of minimal airway obstruction, e.g. in an asthmatic. Accompanying pulmonary haemorrhage has been reported with negative pressure pulmonary oedema [74, 75], and 
probably has a similar mechanism to the bloody sputum reported in swimming, exercise and immersion pulmonary oedema. TOUMPANAKIS et al. [76] studied rats with a resistive valve in their inspiratory breathing circuit and found rapid onset of pulmonary oedema when the rats breathed against an airway resistance. In addition, they identified an injury pattern with inflammatory cells several hours after onset of pulmonary oedema. Histological examination of the lungs demonstrated alveolar haemorrhage, inflammatory cell infiltration in the interstitial tissues and alveoli, and capillary congestion.

\section{Interpretation}

The studies mentioned previously involve lung blood volume effects of immersion, the effects of exercise on pulmonary capillary pressure and stress, evidence for pulmonary oedema related to high-intensity exercise, and the contribution of negative intra-alveolar pressure to pulmonary oedema. It is probable that noncardiogenic pulmonary oedema occurring under a variety of environmental conditions has a common set of factors that contribute to the disorder, including the following. 1) Increased pulmonary blood volume from immersion and, when present, negative intrathoracic pressure. 2) Increased capillary blood volume and a concomitant increase in transcapillary gradient related to the increased capillary blood volume and, when present, a negative alveolar pressure. 3) Increased cardiac output related to exercise with resulting elevation of PAP. 4) Increased left ventricular diastolic pressure and resultant elevated pulmonary venous pressure related to reduced compliance of the ventricle (diastolic dysfunction), which may result from hypertension [77], ageing [78], diabetes [79], and several forms of cardiomyopathy [80, 81]. 5) Hypoxiainduced pulmonary hypertension. Individual contribution of each of these factors varies depending on the exposure. While clear evidence of cardiac and pulmonary abnormalities have not been found [82], individual variation in susceptibility $[8,83]$ due either to variations in capillary strength, left ventricular relaxation, pulmonary vascular reactivity under conditions of exercise, and the instantaneous state of blood and fluid volume are likely to contribute to the development of pulmonary oedema.

\section{Diving-related lung injuries \\ Pulmonary barotrauma}

In recent years, recreational scuba diving has become a popular sport throughout the world. During diving, the surrounding pressure increases proportionally to the depth. At sea level, normal atmospheric pressure or one atmosphere absolute is equivalent to the pressure of a column of $760 \mathrm{mmHg}$. 1 bar corresponds to a pressure of $10 \mathrm{~m}$ seawater, so at a depth of $40 \mathrm{~m}$ seawater the surrounding pressure is 5 bars. Sport divers usually use self-contained underwater breathing apparatus that allows the diver to breathe air supplied from a high-pressure tank carried by the diver and delivered through a pressure regulator that accommodates the changing ambient pressure of the diving environment.

Boyle's law states that if the temperature of a fixed mass of an ideal gas is kept constant, volume and pressure are inversely related. Consequently, when the pressure is doubled, the volume is reduced to half of the original volume.

Pulmonary barotrauma refers to lung injury induced by rapid changes in intrapulmonary pressures related to the surrounding ambient pressure (pressure surrounding the body) during diving. Pulmonary barotrauma may occur even at small pressure difference and includes pneumomediastinum (fig. 2), pneumothorax and (the most feared complication) arterial gas emboli. Pulmonary barotrauma can occur on descent or ascent [84-87].

During descent in breath-hold diving, the gas volume in the lungs is reduced as the surrounding pressure increases. Compression of the lung to volumes below the residual volume will initially result in lung engorgement as blood shifts into the pulmonary vasculature to fill the diminishing gas volume. As compression continues, intrapulmonary pressure will fall below ambient pressure and the negative intrathoracic pressure relative to hydrostatic pressure will result in lung squeeze and pulmonary haemorrhage.

During ascent, according to Boyle's law, the lung volume expands as the surrounding pressure decreases. Therefore, the diver must exhale during ascent in order to equalise the intrapulmonary pressure to the surrounding pressure. When the diver ascends without properly ventilating to expel the expanding gas volume, the lung volume will increase, with overdistension of the alveoli and bronchi leading to lung rupture. Transpulmonary pressure of $95-110 \mathrm{cmH}_{2} \mathrm{O}$ is sufficient to disrupt pulmonary parenchyma and force gas into the interstitium [88, 89]. Lung disease with airways obstruction or air trapping, such as asthma, chronic obstructive airway disease and the existence of lung cysts, are considered risk factors for pulmonary barotrauma [90-93]. However, the most common reason for pulmonary barotrauma is the diver's technique of ascent. It should be emphasised that the risk for pulmonary barotrauma is highest in shallow water diving as, in agreement with Boyle's law, the relative change in volume is maximal while the diver ascends from $10 \mathrm{~m}$ seawater to sea level. When alveolar rupture occurs, gas infiltrates into the 


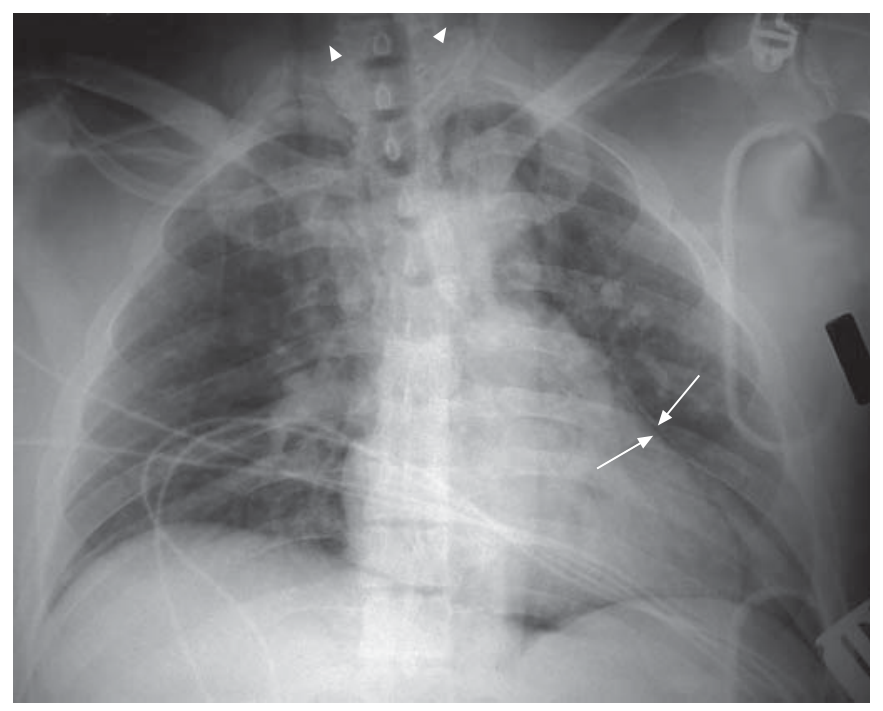

FIGURE 2 Chest radiograph from a diver with pulmonary barotrauma presenting as pneumomediastinum. The border of the anterior mediastinum is pushed away from the heart (arrows) and cervical emphysema can be seen (arrowheads). Bilateral lung infiltrates resulting from aspiration due to drowning are also visible. Image courtesy of T. Neuman, Dept of Emergency Medicine, University of California, San Diego, CA, USA.

peribronchial space and causes pulmonary interstitial emphysema, pneumomediastinum or pneumothorax [94-96]. Gas may also enter the systemic circulation through the disrupted lung vasculature and cause arterial gas emboli $[97,98]$. HARKER et al. [99] described the radiological findings in 31 divers with arterial gas emboli. 13 (42\%) patients had evidence of pulmonary barotrauma demonstrated by pneumomediastinum $(n=8)$, subcutaneous emphysema $(n=3)$, pneumocardium $(n=2)$, pneumoperitoneum $(n=1)$ or pneumothorax $(n=1) .52 \%$ of the divers had radiographic evidence of concomitant drowning. Arterial gas emboli may result from several other mechanisms not related to pulmonary barotrauma, including severe decompression sickness with the development of venous gas emboli that overwhelm the filtering capacity of the pulmonary capillaries, and "paradoxical emboli" via a functional right-to-left shunt, such as a patent foramen ovale [97, 98].

\section{Pneumomediastinum}

Symptoms of pneumomediastinum include a sensation of fullness in the chest, pleuritic chest pain that may radiate to the shoulders, dyspnoea, coughing, hoarseness or a strange voice and dysphagia [87, 100]. On physical examination, crepitation in the neck may be present due to associated subcutaneous emphysema, and a crackling sound may be heard over the heart during systole upon auscultation. Chest and neck radiographs are diagnostic and demonstrate a radiolucent band along the cardiac border (fig. 2) and air in the soft tissues of the neck. Usually no treatment is needed; however, administration of $100 \%$ oxygen to widen the pressure gradient for nitrogen between the bubble and the circulation helps to accelerate reabsorption of extra-alveolar gas [101, 102]. Rarely, tension pneumomediastinum may occur and mediastinotomy may be needed.

\section{Pneumothorax}

Pneumothorax is relatively uncommon, developing in only $\sim 10 \%$ of episodes of pulmonary barotrauma. Usually the diver will present with dyspnoea and pleuritic chest pain [87]. In $\sim 25 \%$ of cases subcutaneous emphysema will be present. Tension pneumothorax may develop, especially when the diver ascends from a significant depth, with haemodynamic instability, hypotension and hypoxaemia requiring immediate pleural decompression.

\section{Arterial gas embolism}

Arterial gas embolism is the most serious potential sequel of pulmonary barotrauma. The specific symptoms and signs produced are dependent upon the final location of gas emboli; the most serious clinical consequences occur with embolisation to the cerebral and coronary arteries. Divers usually present with symptoms within minutes of surfacing or surface with neurological symptoms, such as focal motor or sensory deficit, seizures, loss of consciousness, apnoea and death. Coronary embolism can lead to dysrhythmias, myocardial infarction and/or cardiac arrest. Muco-cutaneous findings may also appear with a 
characteristic cyanotic marbling of the skin and focal pallor of the tongue. Drowning and aspiration of water usually complicate the clinical course of arterial gas embolism. Hyperbaric oxygen is the treatment of choice for arterial gas embolism and patients should be transferred to the nearest hyperbaric oxygen facility as soon as possible. The prognosis is better following early treatment of cerebral air emboli, with a sharp decrease in clinical efficacy after a few hours delay [101-104].

\section{Respiratory decompression sickness}

During diving, the increased ambient pressure increases dissolved gas concentration in the tissues. Towards the end of the dive as the diver ascends with increased inert gas in their tissues, the gases supersaturate and form a gas phase with a risk of free gas. Gas bubbles can form in the tissues or intravascularly in venous blood. Usually the lung serves as a filter and unloads the inert gas during the decompression phase.

The effect of gas bubbles on the lung has mainly been studied in animal models. Venous gas bubbles formed during decompression may cause increased microvascular permeability, leading to pulmonary oedema and haemorrhage. Furthermore, obstruction of pulmonary vasculature by gas emboli may lead to pulmonary hypertension with systemic hypotension and hypoxaemia [105-107].

However, pulmonary decompression sickness is quite rare, since the diving profile in sport diving does not exert a significant decompression stress on the lung. Clinically, the diver presents with cough, chest pain, wheezing, dyspnoea and pharyngeal irritation (the chokes) [87]. Obstruction of right ventricular outflow with acute right-sided cardiac failure (air lock), circulatory collapse and death may ensue [87, 101-108].

Treatment of decompression sickness includes administration of 100\% oxygen and hydration on site with rapid referral for hyperbaric oxygen treatment, which acts by rapid elimination of the gas phase and correction of tissue hypoxia [101-108].

\section{Breath-hold diving}

In breath-hold diving the diver is exposed to hyperoxia during descent and hypoxia during ascent (in a prolonged dive or at the end of a dive in shallow water). Carbon dioxide often remains in the physiological range, probably due to extensive hyperventilation before the apnoea attempt [109-111]. Furthermore, as the diver goes deeper the increased surrounding hydrostatic pressure causes compression of the chest wall and lung squeeze with atelectasis formation, alveolar capillary membrane rupture, fluid filtration and bleeding into the alveolar space $[112,113]$. Indeed, in competitive breath-hold divers there are reports of pulmonary oedema with symptoms of cough, dyspnoea and haemoptysis. In order to prevent pulmonary barotrauma from descent and in order to reach the deepest possible depth, divers try to increase their lung volume before the dive [112-115]. Today, many competitive breath-hold divers use a manoeuvre called glossopharyngeal insufflation to increase lung volume. After maximal inspiration, when total lung capacity is achieved, the diver fills the mouth with air, opens the glottis and forces this air into the lungs (lung packing). Glossopharyngeal insufflation can increase lung volume up to $50 \%$ of vital capacity. The increased lung volume is accompanied by diaphragmatic depression and increased chest circumference [112-115]. However, glossopharyngeal insufflation is not without risks and may cause syncope by reducing venous return with decreased cardiac output with hypotension and may result in pulmonary barotrauma due to increased transpulmonary pressure [112-116]. However, glossopharyngeal insufflation is used by many competitive breath-hold divers with few reports of major complication.

\section{Hypoxic loss of consciousness}

Hypoxic loss of consciousness is an effect of breath-holds diving that is not associated with lung injury. However, it is a well-known accompaniment of breath-hold diving and deserves to be mentioned as it is related to immersion.

\section{Hyperventilation}

Hypercapnia is the major drive for breathing, while hypoxia is considered a weak respiratory stimulus. Therefore, athletes competing for duration of immersed breath holding (static apnoea) typically hyperventilate extensively before the dive. Hyperventilation leads to reduction in carbon dioxide stores in blood and tissues and increases lung oxygen stores by $\sim 250-300 \mathrm{~mL}$, which allows the diver to lengthen their time of apnoea. However, during prolonged breath hold the diver may become hypoxaemic due to progressive reduction in arterial oxygen tension as a result of metabolic consumption and decreasing ambient pressure during ascent, while the carbon dioxide levels are still below the breathing threshold, and loss of consciousness ensues without forewarning followed by drowning (shallow water blackout) [112, 117, 118]. 


\section{Hypoxia of ascent}

During ascent the surrounding water pressure is decreased and, as a result, the alveolar gas pressure is reduced in accordance with Henry's law. During the dive the oxygen fraction is reduced in alveolar gas in concordance with the diver's metabolism. At certain depths, with increased atmospheric pressure, the oxygen fraction is enough to reach partial oxygen pressure in alveolar air that is adequate to maintain normal mental function. However, during ascent when the oxygen fraction in alveolar gas is low, the decreased alveolar gas pressure with the reduced partial oxygen pressure may cause loss of consciousness and drowning. Indeed, drowning incidents with apparent connection to hypoxia of ascent are relatively common among competitive spear fishermen, who perform a relatively deep dive with prolonged breath hold $[112,119,120]$.

\section{Conclusion}

While performing different kinds of sports in an extreme environment, understanding the physiological changes in the cardiovascular system is important in order to better understand risk factors for lung injury and how we can prevent it.

\section{References}

West JB. Fragility of pulmonary capillaries. J Appl Physiol 2013; 115: 1-15.

Naeije R, Chesler N. Pulmonary circulation at exercise. Compr Physiol 2012; 2: 711-741.

West JB. The role of the fragility of the pulmonary blood-gas barrier in the evolution of the pulmonary circulation. Am J Physiol Regul Integr Comp Physiol 2012; 304: R171-R176.

4 West JB, Mathieu-Costello O, Jones JH, et al. Stress failure of pulmonary capillaries in racehorses with exerciseinduced pulmonary hemorrhage. J Appl Physiol 1993; 75: 1097-1109.

$5 \quad$ West JB. Invited review: pulmonary capillary stress failure. J Appl Physiol 2000; 89: 2483-2489.

6 Stickland MK, Welsh RC, Petersen SR, et al. Does fitness level modulate the cardiovascular hemodynamic response to exercise? J Appl Physiol 2006; 100: 1895-1901.

7 Bartesaghi M, Beretta E, Pollastri L, et al. Inter-individual differences in control of alveolar capillary blood volume in exercise and hypoxia. Respir Physiol Neurobiol 2014; 190: 96-104.

8 Trivax JE, Franklin BA, Goldstein JA, et al. Acute cardiac effects of marathon running. J Appl Physiol 2010; 108: $1148-1153$.

9 Bancal C, Arnoult F, Krapf L, et al. Patent foramen ovale and hypoxaemia with or without elevated right heart pressures. Rev Mal Respir 2011; 28: 967-977.

10 Shupak A, Guralnik L, Keynan Y, et al. Pulmonary edema following closed-circuit oxygen diving and strenuous swimming. Aviat Space Environ Med 2003; 74: 1201-1204.

11 Pons M, Blickenstorfer D, Oechslin E, et al. Pulmonary oedema in healthy persons during scuba-diving and swimming. Eur Respir J 1995; 8: 762-767.

12 Koehle MS, Lepawsky M, McKenzie DC. Pulmonary oedema of immersion. Sports Med 2005; 35: 183-190.

13 Biswas R, Shibu PK, James CM. Pulmonary oedema precipitated by cold water swimming. Br J Sports Med 2004; 38 : e36.

14 Adir Y, Shupak A, Gil A, et al. Swimming-induced pulmonary edema: clinical presentation and serial lung function. Chest 2004; 126: 394-399.

15 Lund KL, Mahon RT, Tanen DA, et al. Swimming-induced pulmonary edema. Ann Emerg Med 2003; 41: 251-256.

16 Mahon RT, Kerr S, Amundson D, et al. Immersion pulmonary edema in special forces combat swimmers. Chest 2002; 122: 383-384.

17 Shupak A, Weiler-Ravell D, Adir Y, et al. Pulmonary oedema induced by strenuous swimming: a field study. Respir Physiol 2000; 121: 25-31.

18 Wilmshurst PT, Nuri M, Crowther A, et al. Cold-induced pulmonary oedema in scuba divers and swimmers and subsequent development of hypertension. Lancet 1989; 1: 62-65.

19 Fraser JA, Peacher DF, Freiberger JJ, et al. Risk factors for immersion pulmonary edema: hyperoxia does not attenuate pulmonary hypertension associated with cold water-immersed prone exercise at 4.7 ATA. J Appl Physiol 2011; 110: 610-618.

20 Coulange M, Rossi P, Gargne O, et al. Pulmonary oedema in healthy SCUBA divers: new physiopathological pathways. Clin Physiol Funct Imaging 2010; 30: 181-186.

21 Shearer D, Mahon R. Brain natriuretic peptide levels in six basic underwater demolitions/SEAL recruits presenting with swimming induced pulmonary edema (SIPE). J Spec Oper Med 2009; 9: 44-50.

22 Moon RE, Cherry AD, Stolp BW, et al. Pulmonary gas exchange in diving. J Appl Physiol 2009; 106: 668-677.

23 Zavorsky GS. Evidence of pulmonary oedema triggered by exercise in healthy humans and detected with various imaging techniques. Acta Physiol (Oxf) 2007; 189: 305-317.

24 Hodges AN, Sheel AW, Mayo JR, et al. Human lung density is not altered following normoxic and hypoxic moderate-intensity exercise: implications for transient edema. J Appl Physiol 2007; 103: 111-118.

25 Caillaud C. Interstitial edema does occur with limited adverse effect in the long term. J Appl Physiol 2010; 109: 1279.

26 Bates ML, Farrell ET, Eldridge MW. The curious question of exercise-induced pulmonary edema. Pulm Med 2011; 2011: 361931.

27 Zavorsky GS, Saul L, Decker A, et al. Radiographic evidence of pulmonary edema during high-intensity interval training in women. Respir Physiol Neurobiol 2006; 153: 181-190.

28 Hanel B, Law I, Mortensen J. Maximal rowing has an acute effect on the blood-gas barrier in elite athletes. J Appl Physiol 2003; 95: 1076-1082.

29 Wilmshurst PT. Pulmonary oedema induced by emotional stress, by sexual intercourse, and by exertion in a cold environment in people without evidence of heart disease. Heart 2004; 90: 806-807.

30 Boggio-Alarco JL, Jaume-Anselmi F, Ramirez-Rivera J. Acute pulmonary edema during a triathlon occurrence in a trained athlete. Bol Asoc Med P R 2006; 98: 110-113. 


\section{BMJ Case Rep 2009; pii, bcr04.2009.1764.}

34 Hopkins SR. Point: pulmonary edema does occur in human athletes performing heavy sea-level exercise. J Appl Physiol 2010; 109: 1270-1272.

35 Zavorsky GS, Anholm JD. Mild interstitial pulmonary edema occurs during sea level strenuous exercise. J Appl Physiol 2010; 109: 1276.

36 Friedman PJ. Edema in athletes vs. interstitial edema in anyone. J Appl Physiol 2010; 109: 1277.

37 Pingitore A, Garbella E, Piaggi P, et al. Early subclinical increase in pulmonary water content in athletes performing sustained heavy exercise at sea level: ultrasound lung comet-tail evidence. Am J Physiol Heart Circ Physiol 2011; 301: H2161-H2167.

38 Bussotti M, Di Marco S, Marchese G, et al. Subclinical pulmonary edema in endurance athletes. Monaldi Arch Chest Dis 2012; 77: 76-82.

39 Ma JL, Dutch MJ. Extreme sports: extreme physiology. Exercise-induced pulmonary oedema. Emerg Med Australas 2013; 25: 368-371.

40 Zavorsky GS, Milne EN, Lavorini F, et al. Interstitial lung edema triggered by marathon running. Respir Physiol Neurobiol 2014; 190: 137-141.

41 McKenzie DC, O’Hare TJ, Mayo J. The effect of sustained heavy exercise on the development of pulmonary edema in trained male cyclists. Respir Physiol Neurobiol 2005; 145: 209-218.

42 Luks AM, Robertson HT, Swenson ER. An ultracyclist with pulmonary edema during the Bicycle Race Across America. Med Sci Sports Exerc 2007; 39: 8-12.

43 Zavorsky GS, Saul L, Murias JM, et al. Pulmonary gas exchange does not worsen during repeat exercise in women. Respir Physiol Neurobiol 2006; 153: 226-236.

44 Burnham KJ, Arai TJ, Dubowitz DJ, et al. Pulmonary perfusion heterogeneity is increased by sustained, heavy exercise in humans. J Appl Physiol 2009; 107: 1559-1568.

45 Rosner MH. Exercise-associated hyponatremia. Semin Nephrol 2009; 29: 271-281.

46 Rogers IR, Hew-Butler T. Exercise-associated hyponatremia: overzealous fluid consumption. Wilderness Environ Med 2009; 20: 139-143.

47 Kashyap AS, Anand KP, Kashyap S. Sudden collapse of a young female cross country runner. Br J Sports Med 2006; 40: e11.

48 Hoffman MD, Hew-Butler T, Stuempfle KJ. Exercise-associated hyponatremia and hydration status in 161-km ultramarathoners. Med Sci Sports Exerc 2013; 45: 784-791.

49 Richter S, Betz C, Geiger H. Schwere Hyponatriamie mit Lungen- und Hirnodem bei einer Ironman-Triathletin [Severe hyponatremia with pulmonary and cerebral edema in an Ironman triathlete]. Dtsch Med Wochenschr 2007; 132: $1829-1832$.

50 Siegel AJ. Exercise-associated hyponatremia: role of cytokines. Am J Med 2006; 119: Suppl. 1, S74-S78.

51 Ayus JC, Arieff A, Moritz ML. Hyponatremia in marathon runners. N Engl J Med 2005; 353: $427-428$.

52 Ayus JC, Varon J, Arieff AI. Hyponatremia, cerebral edema, and noncardiogenic pulmonary edema in marathon runners. Ann Intern Med 2000; 132: 711-714.

53 Miles DS, Doerr CE, Schonfeld SA, et al. Changes in pulmonary diffusing capacity and closing volume after running a marathon. Respir Physiol 1983; 52: 349-359.

West J. High altitude medicine. Am J Respir Crit Care Med 2012; 186: 1229-1237.

Swenson ER, Bärtsch P. High altitude pulmonary edema. Compr Physiol 2012; 2: 2753-2757.

6 Hackett PH, Creagh CE, Grover RF, et al. High-altitude pulmonary edema in persons without the right pulmonary artery. N Engl J Med 1980; 302: 1070-1073.

57 Naeije R, De Backer D, Vachiéry JL, et al. High-altitude pulmonary edema with primary pulmonary hypertension. Chest 1996; 110: 286-289.

58 Bärtsch P, Maggiorini M, Ritter M, et al. Prevention of high altitude pulmonary edema by nifedipine. $N$ Engl J Med 1991; 325: 1284-1289.

59 Maggiorini M, Brunner-La Rocca HP, Peth S, et al. Both tadalafil and dexamethasone may reduce the incidence of high-altitude pulmonary edema: a randomized trial. Ann Intern Med 2006; 145: 497-506.

60 Maggiorini M, Mélot C, Pierre S, et al. High altitude pulmonary edema is initially caused by an increased capillary pressure. Circulation 2001; 103: 2078-2083.

61 Guyton AC, Lindsey A. Effect of elevated left atrial pressure and decreased plasma protein concentration on the development of pulmonary edema. Circ Res 1959; 7: 649-657.

62 Hopkins SR, Garg J, Bolar DS, et al. Pulmonary blood flow heterogeneity during hypoxia and high altitude pulmonary edema. Am J Respir Crit Care Med 2005; 171: 83-87.

63 Swenson ER, Maggiorini M, Mongovin S, et al. Pathogenesis of high-altitude pulmonary edema: inflammation is not an etiologic factor. JAMA 2002; 287: 2228-2235.

64 Naeije R, Vanderpool R, Dhakal BP, et al. Exercise-induced pulmonary hypertension: physiological basis and methodological concerns. Am J Respir Crit Care Med 2013; 187: 576-583.

65 La Gerche A, MacIsaac AL, Burns AT, et al. Pulmonary transit of agitated contrast is associated with enhanced pulmonary vascular reserve and right ventricular function at exercise. J Appl Physiol 2010; 109: 1307-1317.

66 Furuichi M, Takeda S, Akada S, et al. Noninvasive positive pressure ventilation in patients with perioperative negative pressure pulmonary edema. J Anesth 2010; 24: 464-468.

67 Chuang YC, Wang CH, Lin YS. Negative pressure pulmonary edema: report of three cases and review of the literature. Eur Arch Otorhinolaryngol 2007; 264: 1113-1116.

68 Regamey J, Mean M, Scherrer U. Oedeme pulmonaire chez un jeune homme sportif [Acute pulmonary oedema in a young sportive man]. Praxis (Bern 1994) 2010; 99: 497-499.

69 Schaffer SA, Manji RA, Kirkpatrick I, et al. Negative pressure pulmonary edema in the coronary care unit. Can J Cardiol 2008; 24: e58-e59. 
101 U.S. Navy Diving Manual. Diagnosis and Treatment of Decompression Sickness and Arterial Gas Embolism. Revision 6. Vol 5. Publication No. NAVSEA 0910-LP-106-0957. Washington DC, U.S. Navy Department, 2008.

102 Longphre JM, Denoble PJ, Moon RE, et al. First aid normobaric oxygen for the treatment of recreational diving injuries. Undersea Hyperb Med 2007; 34: 43-49.

103 Leitch DR, Green RD. Pulmonary barotrauma in divers and the treatment of cerebral arterial gas embolism. Aviat Space Environ Med 1986; 57: 931.

104 Kizer KW. Dysbaric cerebral air embolism in Hawaii. Ann Emerg Med 1987; 16: 535-541.

105 Catron PW, Flynn ET, Yaffe Y, et al. Morphological and physiological responses of the lungs of dogs to acute decompression. J Appl Physiol 1984; 57: 467-474.

106 Atkins CE, Lehner CE, Beck KA, et al. Experimental respiratory decompression sickness in sheep. J Appl Physiol 1988; 65: 1163-1171.

107 Nossum V, Koteng S, Brubakk AO. Endothelial damage by bubbles in the pulmonary artery of the pig. Undersea Hyperb Med 1999; 26: 1-8.

108 Zwirewich CV, Müller NL, Abboud RT, et al. Noncardiogenic pulmonary edema caused by decompression sickness: rapid resolution following hyperbaric therapy. Radiology 1987; 163: 81-82.

109 Muth CM, Radermacher P, Pittner A, et al. Arterial blood gases during diving in elite apnea divers. Int J Sports Med 2003; 24: 104-107. 
110 Lindholm P, Lundgren CE. Alveolar gas composition before and after maximal breath-holds in competitive divers. Undersea Hyperb Med 2006; 33: 463-467.

111 Ferretti G, Costa M, Ferrigno M, et al. Alveolar gas composition and exchange during deep breath-hold diving and dry breath holds in elite divers. J Appl Physiol 1991; 70: 794-802.

112 Lindholm P, Lundgren CE. The physiology and pathophysiology of human breath-hold diving. J Appl Physiol 2009; 106: 284-292.

113 Dujic Z, Breskovic T. Impact of breath holding on cardiovascular respiratory and cerebrovascular health. Sports Med 2012; 42: 459-472.

114 Novalija J, Lindholm P, Loring SH, et al. Cardiovascular aspects of glossopharyngeal insufflation and exsufflation. Undersea Hyperb Med 2007; 34: 415-423.

115 Ferrigno M, Hickey DD, Liner MH, et al. Cardiac performance in humans during breath holding. J Appl Physiol 1986; 60: 1871-1877.

116 Potkin R, Cheng V, Siegel R. Effects of glossopharyngeal insufflation on cardiac function: an echocardiographic study in elite breath-hold divers. J Appl Physiol 2007; 103: 823-827.

117 Craig AB Jr. Causes of loss of consciousness during underwater swimming. J Appl Physiol 1961; 16: 583-586.

118 Craig AB Jr. Summary of 58 cases of loss of consciousness during underwater swimming and diving. Med Sci Sports 1976; 8: 171-175.

119 Landsberg PG. Hyperventilation: an unpredictable danger to the sports diver. In: Lundgren CE, Ferrigno M, eds. The Physiology of Breath-hold Diving. Bethesda, Undersea and Hyperbaric Medical Society, 1987; pp. 256-267.

120 Landsberg PG. South African underwater diving accidents, 1969-1976. S Afr Med J 1976; 50: 2155-2159. 